\title{
Bizarre tail weaponry in a transitional ankylosaur from subantarctic Chile
}

\section{Sergio Soto-Acuña}

Universidad de Chile

Alexander Vargas ( $\nabla$ alexvargas@uchile.cl)

Universidad de Chile

Jonatan Kaluza

Fundación Félix de Azara, CONICET

Marcelo Leppe

Instituto Antártico Chileno - INACH https://orcid.org/0000-0002-1545-8167

Joao Botelho

Pontificia Universidad Católica de Chile

José Palma-Liberona

Pontificia Universidad Católica de Chile

Carolina Gutstein

Universidad de Chile

Roy Fernández

Universidad de Concepción

Hector Ortiz

Universidad de Magallanes

Verónica Milla

Universidad de Concepción

\section{Bárbara Aravena}

Universidad de Chile

\section{Leslie Manríquez}

Universidad de Vale do Rio dos Sinos https://orcid.org/0000-0002-0797-0355

Jhonatan Alarcón-Muñoz

Universidad de Chile

\section{Juan Pino}

Universidad de Chile

\section{Christine Trevisan}

Instituto Nacional Antártico de Chile

Héctor Mansilla

Instituto Nacional Antártico de Chile

Luis Hinojosa 
Universidad de Chile

Vicente Muñoz-Walther

Universidad de Chile

\section{David Rubilar-Rogers}

Museo Nacional de Historia Natural de Chile

\section{Biological Sciences - Article}

Keywords: dinosaurs, tail weapons, anylosaurus, stegosaurus

Posted Date: November 4th, 2021

DOI: https://doi.org/10.21203/rs.3.rs-821192/v1

License: (c) (1) This work is licensed under a Creative Commons Attribution 4.0 International License. Read Full License

Version of Record: A version of this preprint was published at Nature on December 1st, 2021. See the published version at https://doi.org/10.1038/s41586-021-04147-1. 


\section{Bizarre tail weaponry in a transitional ankylosaur from}

\section{subantarctic Chile}

Sergio Soto-Acuña ${ }^{1,9, \dagger}$, Alexander O. Vargas ${ }^{1, \dagger}$, Jonatan Kaluza $^{1,2,3}$, Marcelo A. Leppe ${ }^{1,4}$, Joao F. Botelho ${ }^{1,5}$, José Palma-Liberona ${ }^{1,5}$, Carolina Simon-Gutstein ${ }^{1}$, Roy A. Fernández ${ }^{1,6}$, Héctor Ortiz ${ }^{1,7}$, Verónica Milla ${ }^{1,6}$, Bárbara Aravena1 ${ }^{1}$ Leslie M.E. Manríquez ${ }^{1,8}$, Jhonatan Alarcón-Muñoz ${ }^{1,9}$, Juan Pablo Pino ${ }^{1,9}$, Christine Trevisan ${ }^{1,}$ Héctor Mansilla $^{1}$, Luis Felipe Hinojosa $^{1,9}$, Vicente Muñoz-Walther ${ }^{1}$, and David Rubilar-Rogers ${ }^{1,10}$

${ }^{1}$ Red Paleontológica U-Chile. Departamento de Biología, Facultad de Ciencias, Universidad de Chile, ${ }^{2}$ Fundación Félix de Azara, Argentina, ${ }^{3}$ CONICET, Argentina, ${ }^{4}$ Laboratorio de Paleobiología, Instituto Nacional Antártico Chileno, ${ }^{5}$ Escuela de Medicina Veterinaria, Pontificia Universidad Católica de Chile, ${ }^{6}$ Universidad de Concepción, ${ }^{7}$ Universidad de Magallanes, ${ }^{8}$ Universidad de Vale do Rio dos Sinos, Brasil ${ }^{9}$ Departamento de Ecología, Facultad de Ciencias, Universidad de Chile, ${ }^{9}$ Área Paleontología, Museo Nacional de Historia Natural de Chile.

†email: sesotacu@ug.uchile.cl, alexvargas@uchile.cl

Armoured dinosaurs are well known for forms that evolved specialized tail weapons: paired tail spikes in stegosaurs, and heavy tail clubs in advanced ankylosaurs ${ }^{1}$. Armoured dinosaurs from southern Gondwana are rare and enigmatic, but likely include the earliest branches of Ankylosauria ${ }^{2-4}$. Here, we describe a mostly complete, semiarticulated skeleton of a small ( 2m) armoured dinosaur from the late Cretaceous of Magallanes in southernmost Chile, a region biogeographically related to West Antarctica ${ }^{5}$. Stegouros elengassen gen. et sp. nov. evolved a large tail weapon unlike any dinosaur: A flat, frond-like structure formed by 7 pairs of laterally projecting osteoderms encasing the distal half of the tail. Stegouros shows ankylosaurian cranial characters, but a largely primitive postcranial skeleton, with some stegosaur-like characters. Phylogenetic analyses placed Stegouros in 
Ankylosauria, and specifically related to Kunbarrasaurus from Australia ${ }^{6}$ and Antarctopelta from Antarctica ${ }^{7}$, forming a clade of Gondwanan ankylosaurs that split earliest from all other ankylosaurs. Large osteoderms and specialized tail vertebrae in Antarctopelta suggest it had a tail weapon similar to Stegouros. We propose a new clade, the Parankylosauria, to include the first ancestor of Stegouros but not Ankylosaurus, and all descendants of that ancestor.

Dinosauria Owen, 1842

Ornithischia Seeley, 1887

Thyreophora Nopcsa 1928

Ankylosauria Osborn, 1923

Parankylosauria clade nov. Stegouros elengassen gen. et sp. nov.

Etimology—Stegouros, after the Greek stego (roof) and the Greek uros (tail) in reference to the covered tail; elengassen, after an armoured beast in the mythology of the local Aónik’enk people ${ }^{8}$.

Holotype—A mostly complete skeleton (Fig. 1) whose posterior half (tail, sacrum, pelvic girdle and posterior limbs) is largely articulated, with remaining disarticulated skeleton including axis, cervical and dorsal vertebrae, sternal plates, coracoids, forelimbs (including a partially articulated right manus), osteoderms, and several disarticulated cranial bones. Preservation reflects a single individual (Supplementary Information, Supplementary Fig. 1) and ontogenetic fusion of elements is complete (neural arches, occipital bones, anterior 
and greater trochanter of femur), discarding juvenile status (i.e. an animal with no signs of impending maturity $\left.{ }^{9}\right)$.

Locality and horizon-Río de las Chinas Valley, Estancia Cerro Guido, Magallanes Region, Chilean Patagonia $\left(51^{\circ} \mathrm{S}\right)$. Lower section of Dorotea Formation (upper Campanian - lower Maastrichtian), between $71.7 \pm 1.2 \mathrm{Ma}$ and $74.9 \pm 2.1 \mathrm{Ma}^{10,11}$ (Supplementary Information section 2, Supplementary Fig. 2).

Diagnosis-A small sized $(180-200 \mathrm{~cm})$ slender-limbed armoured dinosaur that differs from all other members of this clade by the presence of a short tail with no more than 26 vertebrae, covered distal to the $14^{\text {th }}$ caudal vertebra by 7 pairs of large osteoderms, the distalmost 5 fused into a flat composite unit. Stegouros can be assigned to Ankylosauria on the basis of medially bowed dentary tooth rows; strongly medially inset maxillary tooth rows; maxilla with a medial process; and short cervicals. Otherwise, the postcranial skeleton lacks ankylosaurian synapomorphies. Stegouros differs from Antarctopelta in its smaller body size; proportionally larger neural canal; longer dorsosacral centra; higher and narrower sacral centra; absence of ossified caudal tendons; teeth with 6 mesial denticles (vs. 7-8 in Antarctopelta); and cingula lacking vertical furrows. Stegouros differs from Kunbarrasaurus in a more curved ulna and ischium (straight in Kunbarrasaurus) and a dorsal maxillo-lacrimal process that is narrower and posteriorly inclined.

Diagnosis of the genus-As for the type species.

Description-Preserved skull elements imply a proportionally large head, although depth vs. width cannot be established (Fig. 1 b-d, Extended Data Fig. 1). Premaxillae and maxillae preserve rostral portions only. Premaxillae are toothless, completely fused at the 
midline (with no suture or indentation), narrow, short, and high, with a deep palatal surface (Fig.1b, c). The maxillae are seamlessly fused to the lacrimals, which are laminar and posteriorly inclined. As in Ankylosauria, the maxillae show a medial process (secondary palate) and strongly inset tooth rows ${ }^{12}$. Maxillary tooth rows begin shortly anterior to the lacrimal, extending under the orbit. The supraoccipital is large, forming the entire upper margin of the foramen magnum, thickening above it into a distinct dorsal shelf (Fig. 1d). The basisphenoid is short ( $<$ basioccipital length). Two unidentified circumorbital skull roof fragments show strongly rugose surfaces ornamented by foramina and grooves, and clear sutures between bones as in Kunbarrasaurus ${ }^{6}$ (not obliterated as in other Ankylosauria $\left.{ }^{13,14}\right)$. The right dentary is sinuous in lateral view, with a medially bowed row of 14 alveoli; the last two show erupted teeth in position (Extended Data Fig. 1). These are leaf-like with high crowns that are mesiodistally asymmetric, and denticles continuous to enamel flutings that reach down to a bulged cingulum. The cingulum is asymmetric ${ }^{13}$ : horizontal in labial view, but an arch in lingual view, that tilts towards baso-mesial (Fig. 1 e, f). The predentary is short and deep, with thin dorsal processes, longer than the ventral processes (Extended Data Fig. 1).

The axis is short as in Ankylosauria ${ }^{14}$, bearing a prominent odontoid process (Extended Data Fig. 2). Cervical centra are wider than long as in ankylosaurs, but laterally concave as in some stegosaurs ${ }^{15}$. Towards posterior, the upward projection of the transverse processes increases, reaching $60^{\circ}$ above horizontal in the dorsal vertebrae. Dorsal vertebrae have tall neural arches with high pedicles, tall neural spines, and prezygapophyses fused into a "U" shape (Fig. 1g). Four true sacral vertebrae fuse anteriorly to two dorsosacrals, the "presacral $\operatorname{rod}^{\prime 13,14}$. Ribs of the dorsosacrals are short and contact the ilium without fusing to it. 
Sacrocaudals are absent (Extended Data Fig. 2). The 13 more proximal caudal vertebrae comprise the more flexible portion of the tail, with remaining vertebrae encased in large osteoderms of the caudal weapon. The $18^{\text {th }}$ caudal is broken, and all vertebrae distal to it are missing (Fig. 1p, Fig. 2, Extended Data Fig. 2, Supplementary movies 1, 2). From the remaining space within the caudal weapon, we estimate no more than 8 missing vertebrae, suggesting at most 26 tail vertebrae: lower than documented in any armoured dinosaur (the lowest being 35 in Scelidosaurus ${ }^{16-20}$ ). Caudal centra are amphiplatyan to platycoelous. Transverse processes are long (about twice the neural spine) and are present beyond midlength of the tail. Neural spines of caudals 7-12 are slightly thickened distally, and shorter than the haemal arches. Posterior to the $12^{\text {th }}$ caudal, the centra show a ventral groove and are equally long than wide, but also very low. A digital endocast of the caudal weapon reveals a notably flattened interior space (Supplementary Movie 3). CT-scans show the prezygapophyses of caudals 15-18 are short, while the postzygapophyses extend caudally over the following centrum, fusing medially into a structure that is wedge-like in dorsal view, with a corresponding " $v$ "-shaped space between the prezygapophyses of the following vertebra (Fig. 2d-f). No ossified tendons are present.

Scapulae were not preserved. The coracoids have a well-preserved scapular margin, discarding fusion to the scapula. Sternal plates are unfused with long tubular caudolateral process (Extended Data Fig. 3). The humerus has a slender diaphysis but mediolaterally expanded epiphyses, and a well-developed, anteriorly directed deltopectoral crest (Fig. 1h, i). A well-defined descending ridge along the caudolateral margin of the humerus includes a weak tubercle at its proximal end, at the same position as the triceps tubercle of Stegosauria ${ }^{21}$. The radius is slender, while the ulna is bowed and proximally expanded, with 
a well-developed olecranon (Fig. 1j). The hand of Stegouros presents definitive hoof-like unguals (unlike comparatively sharp unguals of Scelidosaurus ${ }^{15}$ ). The partially articulated right hand shows reduction to only two phalanges in digit II, as in Stegosauria ${ }^{17}$, with a flattened disc-like non-ungual (Fig. 1k). Other flat, disc-shaped phalanges were found disarticulated but associated to both hands. The left hand preserves a little u-shaped carpal attached to the fifth metacarpal, whose anatomical position and shape suggest it is an ulnare (Extended Data Fig. 3). The ilium shows a long preacetabular process that is strongly anterolaterally deflected (Fig. 11, Extended Data Fig. 4). The shape and relative positions of the supracetabular shelf (lateral process) and postacetabular process are very similar to Stegosauria, suggesting medial rotation of the latter during ontogeny ${ }^{22}$. The ischium is long and lacking an obturator process and ischial symphysis. It tapers distally, bending slightly at mid-length (Extended Data Fig. 4). No pubes were preserved. Femora are straight and only slightly longer than the tibiae (Fig. $1 \mathrm{~m}, \mathrm{n}$ ), with a reduced ridge-like fourth trochanter, and anterior trochanter fused to the greater trochanter (Extended Data Fig. 4). Both feet are complete and articulated. They do not spread distally, showing more extensive proximal contact surfaces between metatarsals III and IV than Stegosauria and Ankylosauria ${ }^{17,23}$ (Fig. 1o). There is no reduction in pedal phalangeal formula, although the distalmost nonunguals of digits III and IV are flattened and disc-shaped. All pedal unguals are hoof-like.

No cranial osteoderms were found. A small $(19 \mathrm{~mm})$ flat osteoderm was found near the axis. Eight medium-sized (40-50 mm) elliptical and keeled osteoderms (Extended Data Fig. 4) resemble flank scutes of other armoured dinosaurs ${ }^{20,24}$ but were not clearly associated to skeletal elements, except for one preserved near the neural arch of a dorsal vertebra. No large cervical osteoderms were found; four small osteoderms $(15-20 \mathrm{~mm})$ with higher, 
acuminate keels were found clustered together near the left manus. Numerous ossicles (small, 4-5 mm osteoderms) were scattered around all skeletal elements. These are almost square oblate spheroids ornamented by pitting in the external surface, and strong orthogonal fibers on the inner side. At the anterior sacrum, the dorsal space between the ilium and the tip of the sacral neural spines is covered by a continuous layer of thin dermal bone with vascular furrows and pits (Fig. 11, Extended Data Fig. 4). Two pairs of small semiconical osteoderms with high, acuminate keels ${ }^{25}$ and concave inner surfaces were found associated to the anterior tail. The 7 pairs of lateral osteoderms of the tail weapon are clearly in anatomical position. The first (most proximal) pair in the series have an acuminate keel with a caudo-laterally slanted apex, a flattened dorsal surface (more conical ventrally), and a markedly concave inner medial surface. Their posterior ventral aspect is fused to smaller semiconical osteoderms like those of the proximal tail, pointing ventrolaterally and posterior (Supplementary Movie 1). The following pair of osteoderms are similar, but larger (covering two entire vertebrae), flatter, and lacking the smaller ventral osteoderms (Fig. 2, Supplementary Movie 1). The next 5 pairs of osteoderms are flattened and fused to each other at their anterior-posterior contact surfaces, giving each osteoderm a roughly pentagonal appearance in upper view, with laterally projecting apexes. They conform a large frond-like structure covering the tail dorsolaterally, and also ventrally towards its distalmost end (Supplementary Movies 1 and 2). Two small knob-like structures at the distal tip likely represent an $8^{\text {th }}$ pair of very small osteoderms. At the appendicular skeleton, a small rounded keeled osteoderm with a concave inner surface was found appressed to the upper right ulna, along with a flat subtriangular osteoderm (Extended Data Fig. 4). Keeled osteoderms were found at the lateral side of both feet (three on the left foot, two on the right; Fig. 10). 


\section{Discussion}

Stegouros shows ankylosaurian skull characters, but slender limbs; most postcranial characters are primitive for Eurypoda (Stegosauria + Ankylosauria), and a few resemble Stegosauria. We carried out phylogenetic analyses with 5 different datasets modified from recent studies focusing on Ornithischia ${ }^{3}$, armoured dinosaurs ${ }^{20}$, Stegosauria ${ }^{26}$, and Ankylosauria ${ }^{27,28}$. In all datasets, Stegouros was found to be closer to Ankylosauria than to Stegosauria, and further grouped with the basal ankylosaurs Kunbarrasaurus and Antarctopelta forming a monophyletic clade that split earliest from all other Ankylosauria (Fig 3, Extended Data Table 1, Supplementary Information). It is worth noting that four of the five modified datasets ${ }^{3,20,26,27}$ supported Stegosauria as sister of Ankylosauria (as in most studies $\left.{ }^{3,21,29}\right)$, including a dataset that had previously supported a different result ${ }^{20}$.

Previous to Stegouros, relationships among Gondwanan ankylosaurs have been enigmatic because only Kunbarrasaurus from the late Lower Cretaceous of Australia ${ }^{6,30}$ was represented by a well-preserved skeleton. Kunbarrasaurus includes a skull with primitive characters $^{6}$, but most of the tail and distal limbs are missing. Like Stegouros, Kunbarrasaurus is small-sized $(\sim 2,5 \mathrm{~m})$, maxillary tooth rows extend under the orbit ${ }^{6}$, osteoderms are present on the $\operatorname{limbs}^{30}$, and a thin layer of dermal bone covers the sacrum ${ }^{30}$. Stegosauria have a superficially similar sacral covering, but it is formed by the expanded transverse processes of the sacral vertebrae ${ }^{31}$, while the pelvic shield of other Ankylosauria is different, formed by a mosaic of fused osteoderms, that additionally covers the ilium ${ }^{32,33}$. Both Stegouros and Kunbarrasaurus show a slender humerus with a descending ridge, and 
a supracetabular process that is semicircular in dorsal view ${ }^{30}$, which are usually found in Stegosauria $^{31}$ and could thus be primitive characters for Eurypoda. Antarctopelta from the late Campanian of the Antarctic peninsula is a larger ankylosaur ( $4 \mathrm{~m})$ known from a very partial skeleton $(\sim 15 \%)^{34}$. Both Stegouros and Antarctopelta are primitive in showing slender metatarsi and no sacrocaudals (Extended Data Fig. 7, Supplementary Information). Some vertebrae of Antarctopelta are unusual for Ankylosauria, even leading to discussion that they could belong to marine reptiles ${ }^{3,35}$, but comparison to Stegouros confirms that they are caudal vertebrae (Supplementary Information). Both dinosaurs present uniquely specialized vertebrae with a flattened centrum and a ventral groove, which are found within the caudal weapon of Stegouros (Extended Data Fig. 5). Large enigmatic osteoderms of Antarctopelta $^{7}$ show a marked medial concavity and an acuminate keel with a slanted apex, resembling the large caudal weapon osteoderms of Stegouros (Extended Data Figs. 6; Supplementary Information). Combined with the flattened distal caudal centra, we infer that Antarctopelta had a similar weapon. A close relationship of Antarctopelta with Stegouros is plausible given their similar age, paleogeographic proximity, and evidence of intercontinental dispersal of flora and fauna between the Antarctic peninsula and southern South America during the late Cretaceous s,30,36 $^{5,3}$

Few flank osteoderms were recovered for both Stegouros and Antarctopelta ${ }^{7}$, which may reflect light trunk armour as documented in Kunbarrasaurus (where it is preserved in $\left.\operatorname{situ}^{36}\right)$. Flat plates of broken dermal bone in Antarctopelta may represent fragments of a sacral covering like that of Kunbarrasaurus and Stegouros (Extended Data Fig. 8), a potentially derived trait shared by all three taxa. All three also share the presence of numerous small ossicles with a pattern of orthogonal striae on the inner side, that are 
unique among armoured dinosaurs ${ }^{37,38}$, and teeth that have denticles confluent with enamel ridges, reaching basally to a bulged and asymmetric cingulum (Extended Data Fig. 9). The north american ankylosaur Edmontonia has similar teeth ${ }^{39}$, but probably convergent given its distant position in phylogenetic analyses.

Taking into account that Stegouros is likely related to other basal ankylosaurs from southern Gondwana, we propose the clade Parankylosauria ("at the side of Ankylosauria") to include the first ancestor of Stegouros but not Ankylosaurus, and all descendants of that ancestor. Conversely, we propose the clade Euankylosauria ("true Ankylosauria") for the first ancestor of Ankylosaurus but not Stegouros, and all its descendants (Fig. 3). The evidence for slender limbs in Parankylosauria suggests that stout limbs and broad feet (the namesake of Eurypoda) are actually convergent between Euankylosauria and Stegosauria. The generally primitive postcranium of Parankylosauria also implies that ankylosaurian specializations evolved first in the skull. Tail clubs of Ankylosaurinae must have evolved independently from the tail weapon of Stegouros, since closer relatives of Ankylosaurinae like Nodosauridae and even basal Ankylosauridae had no specialized tail weapon ${ }^{40}$ (Fig. 3). In Ankylosauridae, long prezygapophyseal articulations stiffen the distal tail, which becomes the handle of the tail club in Ankylosaurine ${ }^{40}$. The tail of Stegouros reflects a different evolutionary pathway, with short prezygapophyses, and a remarkably shorter tail that is stiffened through osteoderm fusion (Fig. 3b). Among amniotes, herbivores with osteoderms and stiff trunks are more likely to evolve specialized tail weapons ${ }^{1,41}$, and armoured dinosaurs in particular are the only clade to have evolved three different kinds of tail weapons: paired spikes (thagomizers) in stegosaurs, clubs in ankylosaurines, and the "macuahuitl" of Stegouros (our suggested term, after the Aztec war club). The 
Parankylosauria must have originated before the earliest record of Euankylosauria, some 167 mya, in the mid-Jurassic (Fig. 3, Supplementary Information). After final separation of Laurasia and Gondwana in the late Jurassic, different clades of Ankylosauria may have prevailed in each supercontinent. These and other possibilities raised by Stegouros illustrate that much still remains unknown about the evolution of armoured dinosaurs, especially in Gondwana $^{42}$.

\section{References}

1 Arbour, V. M. \& Zanno, L. E. The evolution of tail weaponization in amniotes. Proc. R. Soc. B 285, 20172299, doi:doi:10.1098/rspb.2017.2299 (2018).

2 Thompson, R. S., Parish, J. C., Maidment, S. C. \& Barrett, P. M. Phylogeny of the ankylosaurian dinosaurs (Ornithischia: Thyreophora). J Syst Palaeontol 10, 301-312 (2012).

3 Arbour, V. M., Zanno, L. E. \& Gates, T. Ankylosaurian dinosaur palaeoenvironmental associations were influenced by extirpation, sea-level fluctuation, and geodispersal. Palaeogeography, Palaeoclimatology, Palaeoecology 449, 289-299 (2016).

4 Wiersma, J. P. \& Irmis, R. B. A new southern Laramidian ankylosaurid, Akainacephalus johnsoni gen. et sp. nov., from the upper Campanian Kaiparowits Formation of southern Utah, USA. PeerJ 6, e5016 (2018).

5 Reguero, M. A. \& Goin, F. J. Paleogeography and biogeography of the Gondwanan final breakup and its terrestrial vertebrates: New insights from southern South America and the "double Noah's Ark" Antarctic Peninsula. J South Am Earth Sci 108, 103358 (2021).

6 Leahey, L. G., Molnar, R. E., Carpenter, K., Witmer, L. M. \& Salisbury, S. W. Cranial osteology of the ankylosaurian dinosaur formerly known as Minmi sp.(Ornithischia: Thyreophora) from the Lower Cretaceous Allaru Mudstone of Richmond, Queensland, Australia. PeerJ 3, e1475 (2015).

7 Salgado, L. \& Gasparini, Z. Reappraisal of an ankylosaurian dinosaur from the Upper Cretaceous of James Ross Island (Antarctica). Geodiversitas 28, 119-135 (2006).

8 Claraz, J., Casamiquela, R. M. \& Hux, M. Diario de viaje de exploración al Chubut, 18651866. (Ediciones Marymar, 1988).

9 Hone, D. W. E., Farke, A. A. \& Wedel, M. J. Ontogeny and the fossil record: what, if anything, is an adult dinosaur? Biol Lett 12, 20150947, doi:10.1098/rsbl.2015.0947 (2016).

10 Gutiérrez, N. M. et al. Tectonic events reflected by palaeocurrents, zircon geochronology, and palaeobotany in the Sierra Baguales of Chilean Patagonia. Tectonophysics 695, 76-99 (2017).

11 Manríquez, L. M., Lavina, E. L., Fernández, R. A., Trevisan, C. \& Leppe, M. A. CampanianMaastrichtian and Eocene stratigraphic architecture, facies analysis, and 
paleoenvironmental evolution of the northern Magallanes Basin (Chilean Patagonia). J South Am Earth Sci 93, 102-118 (2019).

12 Raven, T. J. \& Maidment, S. C. R. The systematic position of the enigmatic thyreophoran dinosaur Paranthodon africanus, and the use of basal exemplifiers in phylogenetic analysis. PeerJ 6, e4529, doi:10.7717/peerj.4529 (2018).

13 Coombs, W. \& Maryanska, T. in The Dinosauria (eds Weishampel DB, Dodson P, \& Osmolka H) 456-483 (University of California Press, 1990).

14 M, V., Maryańska, T. \& Weishampel, D. B. in The dinosauria (eds DB Weishampel, Peter Dodson, \& Halszka Osmólska) 464-477 (University of California Press, 2004).

Pereda-Suberbiola, X., Galton, P. M., Mallison, H. \& Novas, F. A plated dinosaur (Ornithischia, Stegosauria) from the Early Cretaceous of Argentina, South America: an evaluation. Alcheringa: An Australasian Journal of Palaeontology 37, 65-78 (2013).

Colbert, E. H. A Primitive Ornithischian Dinosaur fromthe Kayenta Formation of Arizona. 55 (Museum of Northern Arizona Press, 1981).

17 Gilmore, C. W. Osteology of the armoured Dinosauria in the United States National Museum, with special reference to the genus Stegosaurus. United States National Museum Bulletin, 1-143 (1914).

18 Maidment, S. C. R., Brassey, C. \& Barrett, P. M. The Postcranial Skeleton of an Exceptionally Complete Individual of the Plated Dinosaur Stegosaurus stenops (Dinosauria: Thyreophora) from the Upper Jurassic Morrison Formation of Wyoming, U.S.A. PLoS ONE 10, e0138352, doi:10.1371/journal.pone.0138352 (2015).

19 Maryanska, T. Ankylosauridae (Dinosauria) from MongoliaAnkylosauridae (Dinosauria) from Mongolia. Palaeontol Pol 37, 85-151 (1977).

20 Norman, D. B. Scelidosaurus harrisonii from the Early Jurassic of Dorset, England: the dermal skeleton. Zool J Linn Soc 190, 1-53 (2020).

21 Sereno, P. C. The evolution of dinosaurs. Science 284, 2137-2147 (1999).

22 Carpenter, K., DiCroce, T., Kinneer, B. \& Simon, R. Pelvis of Gargoyleosaurus (Dinosauria: Ankylosauria) and the origin and evolution of the ankylosaur pelvis. PLOS ONE 8, e79887 (2013).

23 Currie, P. J., Badamgarav, D., Koppelhus, E. B., Sissons, R. \& Vickaryous, M. K. Hands, feet, and behaviour in Pinacosaurus (Dinosauria: Ankylosauridae). Acta Palaeontol Pol 56, 489504 (2011).

24 Main, R. P., de Ricqlès, A., Horner, J. R. \& Padian, K. The evolution and function of thyreophoran dinosaur scutes: Implications for plate function in stegosaurs. Paleobiology 31, 291-314, doi:10.1666/0094-8373(2005)031[0291:TEAFOT]2.0.CO;2 (2005).

25 Burns, M. E. \& Currie, P. J. External and internal structure of ankylosaur (Dinosauria, Ornithischia) osteoderms and their systematic relevance. J Vertebr Paleontol 34, 835-851 (2014).

26 Raven, T. J. \& Maidment, S. C. A new phylogeny of Stegosauria (Dinosauria, Ornithischia). Palaeontology 60, 401-408 (2017).

27 Han, F., Forster, C. A., Xu, X. \& Clark, J. M. Postcranial anatomy of Yinlong downsi (Dinosauria: Ceratopsia) from the Upper Jurassic Shishugou Formation of China and the phylogeny of basal ornithischians. J Syst Palaeontol 16, 1159-1187 (2018).

28 Loewen M.A., K. J. I. The evolution and biogeographic distribution of Ankylosauria: New insights from a comprehensive phylogenetic analysis. Journal of Vertebrate Paleontology, Program and Abstracts 2013:, 25 (2013).

29 Sereno, P. C. Phylogeny of the bird-hipped dinosaurs (Order Ornithischia). Natl Geogr Res 2, 234-256 (1986). 
30 Molnar, R. E. An ankylosaur (Ornithischia) from the Lower Cretaceous of southern Queensland. Memoirs of the Queensland Museum 20, 77-87 (1980).

31 Maidment, S. C., Norman, D. B., Barrett, P. M. \& Upchurch, P. Systematics and phylogeny of Stegosauria (Dinosauria: Ornithischia). J Syst Palaeontol 6, 367-407 (2008).

32 Arbour, V. M., Burns, M. E. \& Currie, P. J. A review of pelvic shield morphology in ankylosaurs (Dinosauria: Ornithischia). J Paleontol 85, 298-302 (2011).

33 Blows, W. T. in The Armored Dinosaurs (ed K. Carpenter) 363 (Indiana University Press, 2001).

34 Olivero, E., Gasparini, Z., Rinaldi, C. \& Scasso, R. in International symposium on Antarctic earth sciences. 5. 617-622.

35 Lamanna, m. c. et al. Late Cretaceous non-avian dinosaurs from the James Ross Basin, Antarctica: description of new material, updated synthesis, biostratigraphy, and paleobiogeography. Advances in Polar Science, 228-250 (2019).

36 Murray, A., Riguetti, F. \& Rozadilla, S. New ankylosaur (Thyreophora, ornithischia) remains from the Upper Cretaceous of Patagonia. J South Am Earth Sci 96, 102320 (2019).

37 de Ricqlès, A., Suberbiola, X. P., Gasparini, Z. \& Olivero, E. Histology of dermal ossifications in an ankylosaurian dinosaur from the Late Cretaceous of Antarctica. Publicación Electrónica de la Asociación Paleontológica Argentina 7 (2001).

38 Molnar, R. E. in The armored dinosaurs (ed K Carpenter) 341-362 (Indiana University Press, 2001).

39 Jr., C. W. in Dinosaur Systematics: Approaches and Perspectives (eds Carpenter K \& Currie PJ) 269-279 (Cambridge University Press, 1990).

40 Arbour, V. M. \& Currie, P. J. Ankylosaurid dinosaur tail clubs evolved through stepwise acquisition of key features. J Anat 227, 514-523 (2015).

41 Arbour, V. M. \& Zanno, L. E. Tail weaponry in ankylosaurs and glyptodonts: an example of a rare but strongly convergent phenotype. The Anatomical Record 303, 988-998 (2020).

42 Maidment, S. C., Raven, T. J., Ouarhache, D. \& Barrett, P. M. North Africa's first stegosaur: implications for Gondwanan thyreophoran dinosaur diversity. Gondwana Res 77, 82-97 (2020). 


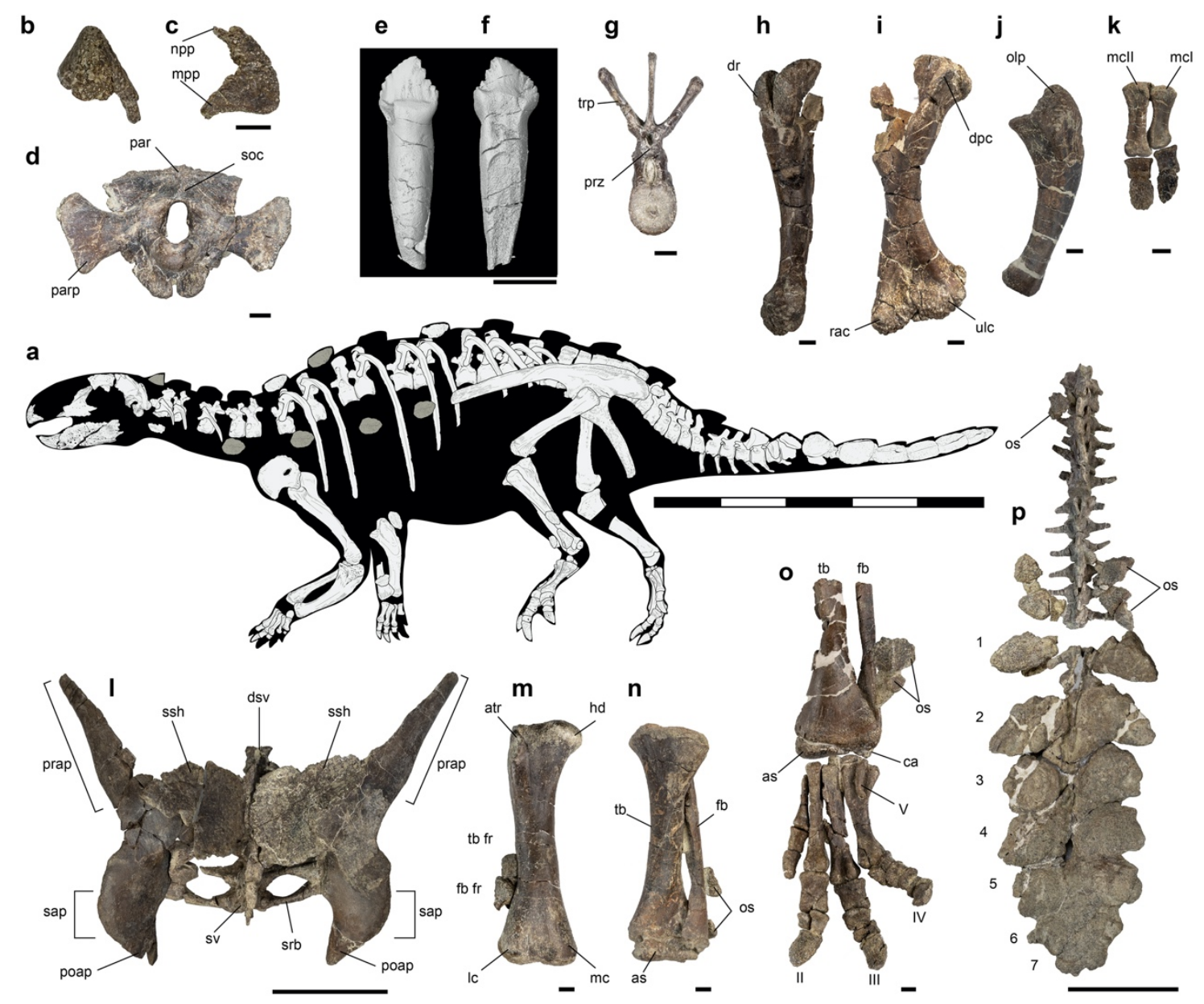

Fig.1 Skeletal anatomy of Stegouros elengassen gen. et sp. nov. a, preserved elements of the skeleton in CPAP-3165. Position of osteoderms in gray shade is speculative. b, c, Rostral portion of premaxilla, dorsal and right lateral views. d, Occipital complex in caudal view. e, f, Cheek tooth, labial and lingual views. g, Mid dorsal vertebra, anterior view. h, i, Left humerus, lateral and anterior views. j, Left ulna, lateral view. k, Partial right hand, dorsal view. l, Pelvis, dorsal view. m, Right femur, anterior view. n, Left tibia and fibula, anterior view. o, Articulated left foot, ventral view. p, articulated tail with caudal weapon (osteoderm pairs 1-7). Scale bars, a-c, g-k, m-o $1 \mathrm{~cm}$; e, f $5 \mathrm{~mm}$; 1, p $10 \mathrm{~cm}$. as, astragalus; atr, anterior trochanter; dpc, deltopectoral crest; dr, descending ridge; dsv, dorsosacral vertebra; fb, fibula; mcI, metacarpal I; mcII, metacarpal II; mpp, maxillary process of premaxilla; npp, nasal process of premaxilla; olp, olecranon process; os, osteoderms;-par, parietal; parp, paraoccipital process; poap; postacetabular process; prap, preacetabular process; prz, prezygapophysis; rac, radial condyle; sap, supracetabular process; ssh, sacral shield; soc, supraoccipital; tb, tibia; trp, transverse process; ulc, ulnar condyle. 


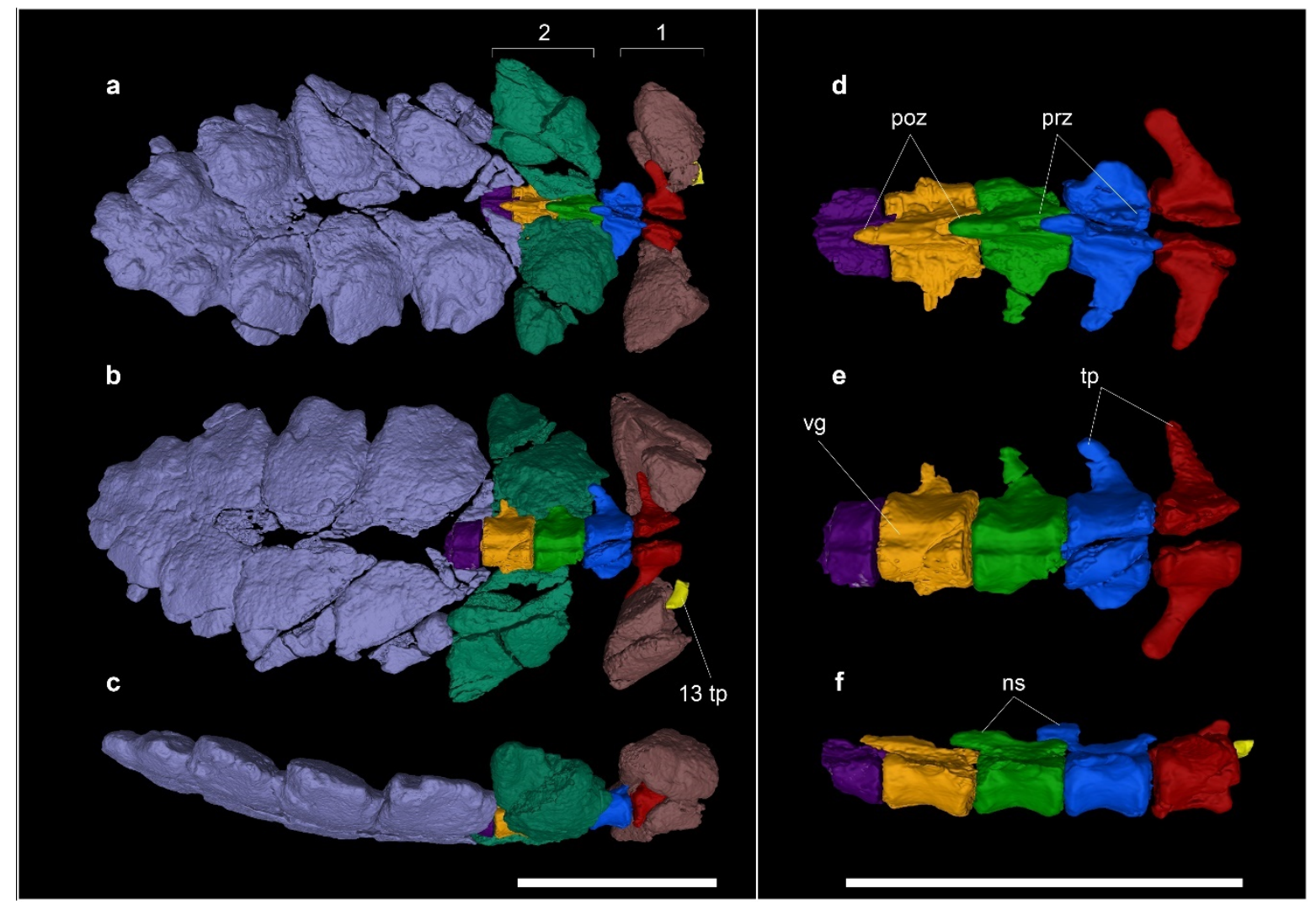

Fig.2 Caudal weapon of Stegouros elengassen gen. et sp. nov. a-c, 3D reconstruction of the caudal weapon obtained through the digital segmentation of a CT scan volume, in dorsal, ventral and right lateral views. d-f, preserved distal caudal vertebrae (number 14 to 18) in dorsal, ventral and right lateral views, showing a ventral groove and elongate postzygapophyses. Scale bar $=10$ cm. 1-2, first and second osteoderm pair; $13 \mathrm{tp}$, transverse process of the $13^{\text {th }}$ caudal vertebra; $n s$, neural spine; prz, prezygapophysis; poz, postzygapophyses; tp, transverse process; vg: ventral groove. 
a

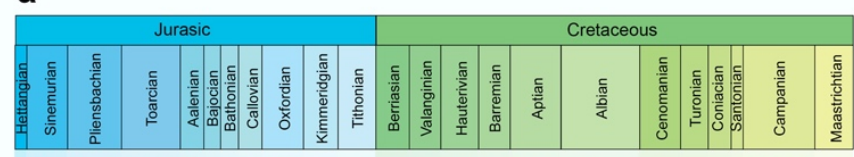

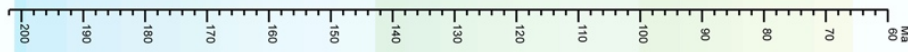

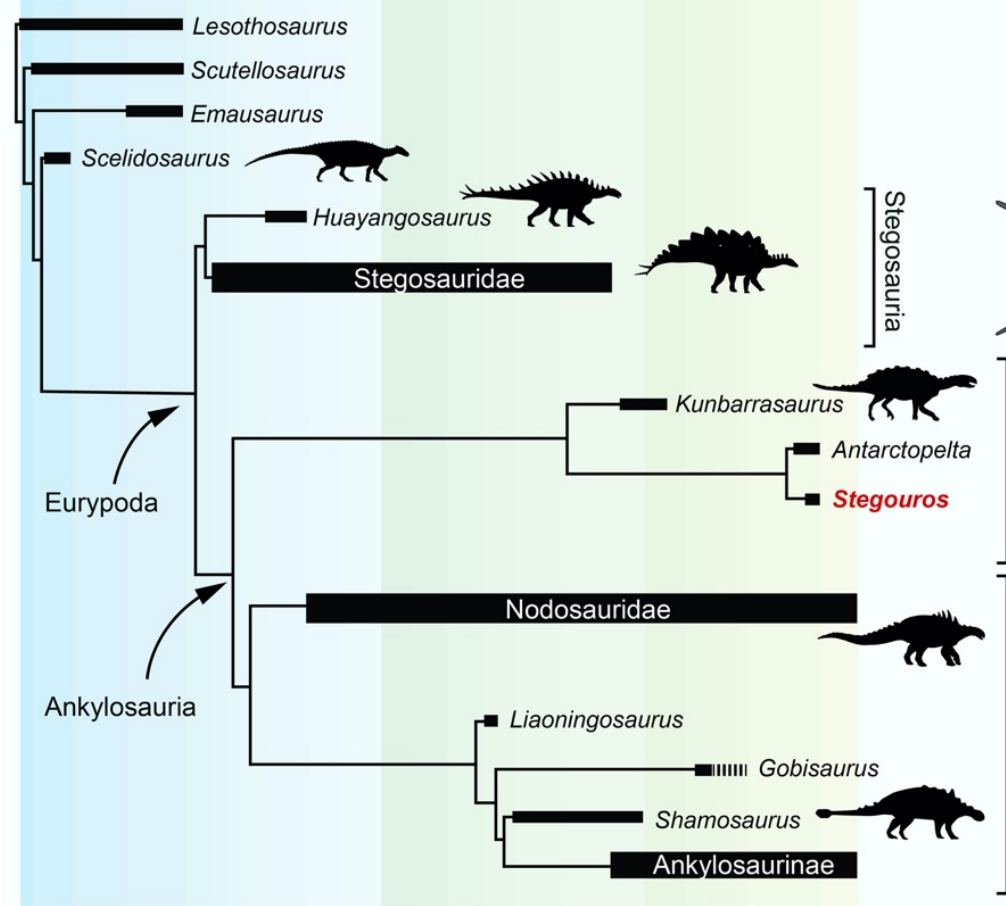

b

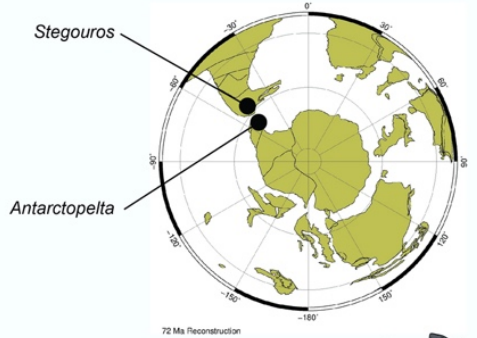

C

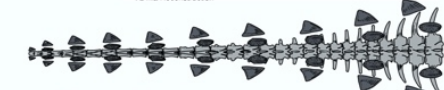

Early-diverging thyreophorans
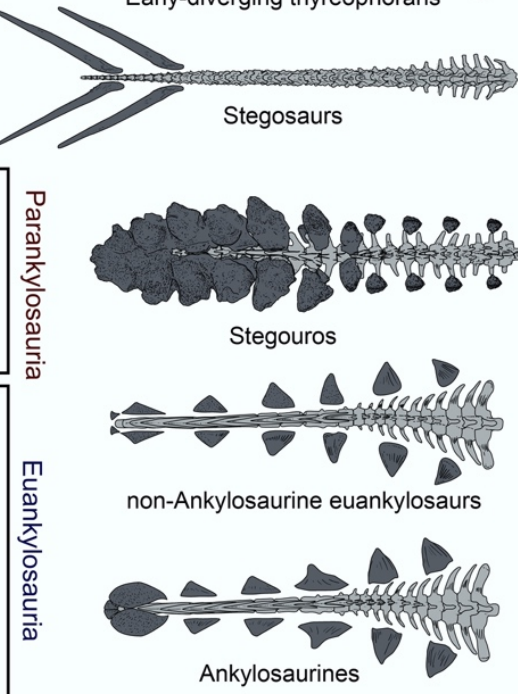

Fig. 3. Fig. 3. Evolution of armoured dinosaurs and their tail weaponry. a, upon including Stegouros, phylogenetic time-calibrated analyses based on different modified matrices support the monophyly of Parankylosauria (Gondwanan Ankylosaurs) and their early split from all other ankylosaurs (Euankylosauria). Most (but not all) analyses also supported Ankylosauria as sister to Stegosauria, and a monophyletic Nodosauridae. b, distribution of Parankylosauria findings in Gondwana during the Cretaceous (map obtained from ODSN Plate Tectonic Reconstruction Service). c, Armoured dinosaurs are the only amniotes to have evolved three different specialized tail weapons in Stegosauria, Stegouros, and Ankylosaurinae. 


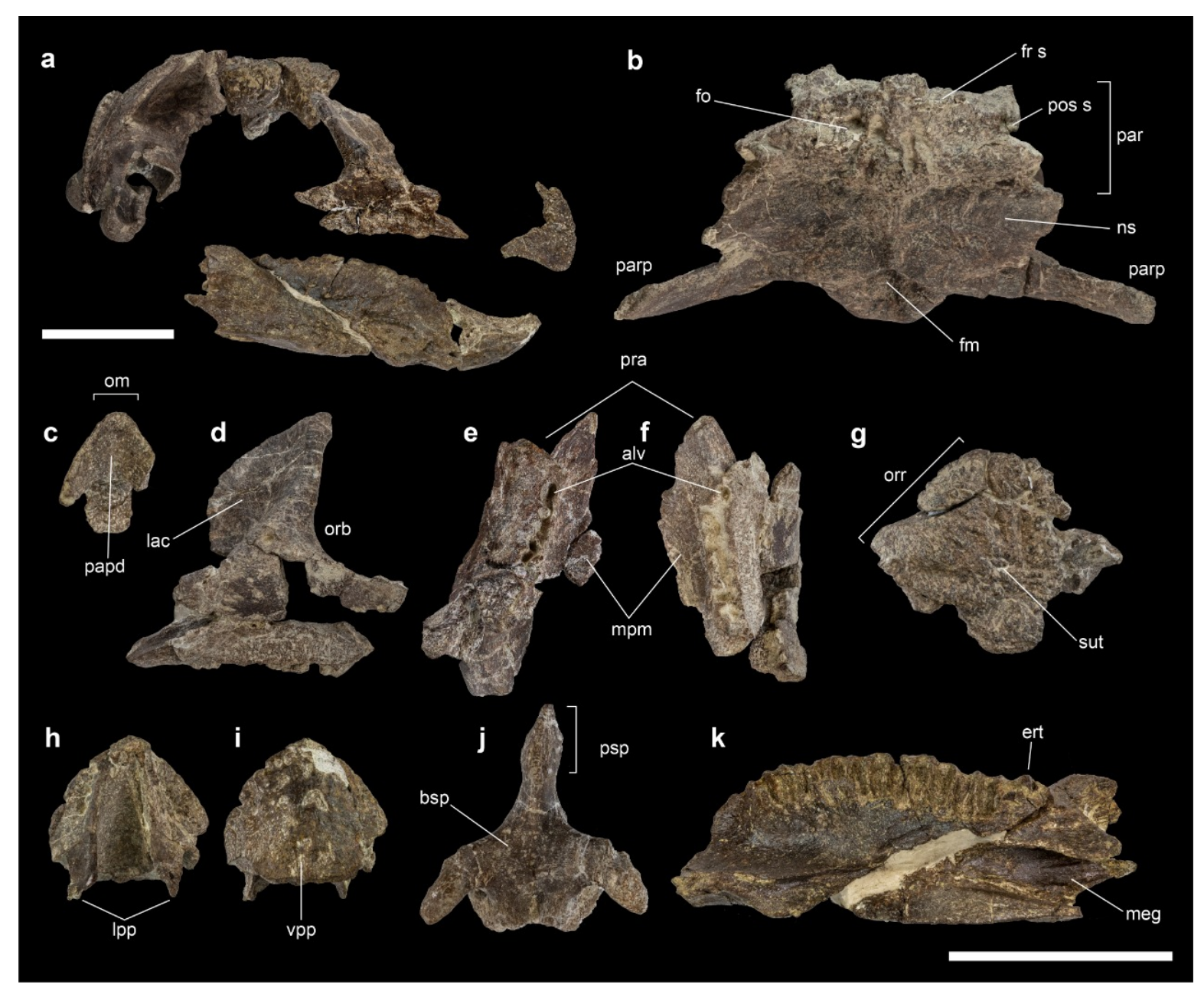

Extended Data Fig. 1 Cranial bones of Stegouros elengassen gen. et sp. nov. a, skull in lateral view. b, posterior skull in dorsal view. c, premaxilla in ventral view. d, left maxilla lateral view. e, $\mathbf{f}$, both maxillae in ventral view. $\mathbf{g}$, right? supraorbital dorsal view. $\mathbf{h}, \mathbf{i}$, predentary in oclusal and ventral views. $\mathbf{j}$, basisphenoid in palatal view. $\mathbf{k}$, right dentary in lingual view. Scale bars $=10 \mathrm{~cm}$. fm, foramen magnum; fo, foramina; fr s, frontal suture; lpp, lateral process of predentary; meg, meckelian groove; mpm, medial process of maxilla; ns, nuchal shelf; om, oral margin; orb, orbit; orr, orbital rim; papd, palatal surface of premaxilla; par, parietal; parp, paroccipital process; pos, postorbital suture; pra, premaxillary articulation; psp, parasphenoid; so, supraorbital; sut, suture; ert, erupted tooth; vpp, ventral process of predentary. 


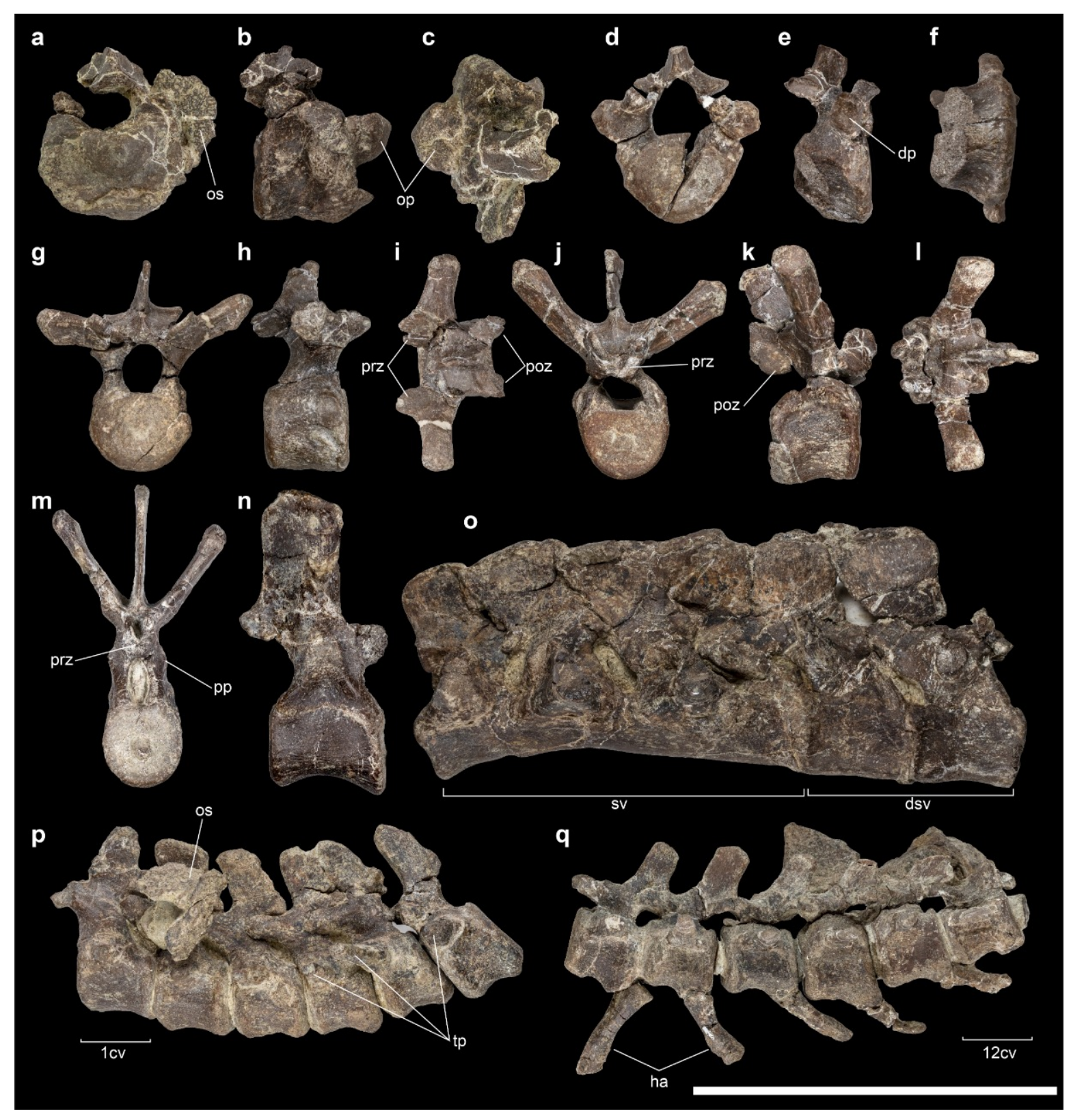

Extended Data Fig. 2 Postcranial axial skeleton of Stegouros elengassen gen. et sp. nov. a, b, axis in anterior and right lateral views. d-f, anterior cervical vertebra in anterior, right lateral and ventral views. g-i, posterior cervical vertebra in anterior, right lateral and dorsal views. $\mathbf{j}-\mathbf{l}$, anterior dorsal vertebra in anterior, right lateral and dorsal views. $\mathbf{m}, \mathbf{n}$, posterior dorsal vertebra in anterior and right lateral views. $\mathbf{0}$, synsacral vertebrae in right lateral view. $\mathbf{p}$, anterior caudal vertebrae in right lateral view. q, posterior caudal vertebrae in right lateral view. Scale bar $=10 \mathrm{~cm}$. $1 \mathrm{cv}$, first caudal vertebra; $12 \mathrm{cv}, 12^{\text {th }}$ caudal vertebra; dp, diapophysis; dsv, dorsosacral vertebrae; ha, haemal arches; op, odontoid process; os, osteoderm; poz, postzygapophyses; pp, parapophysis; prz, prezygapophyses; sv, sacral vertebrae; tp, transverse process. 


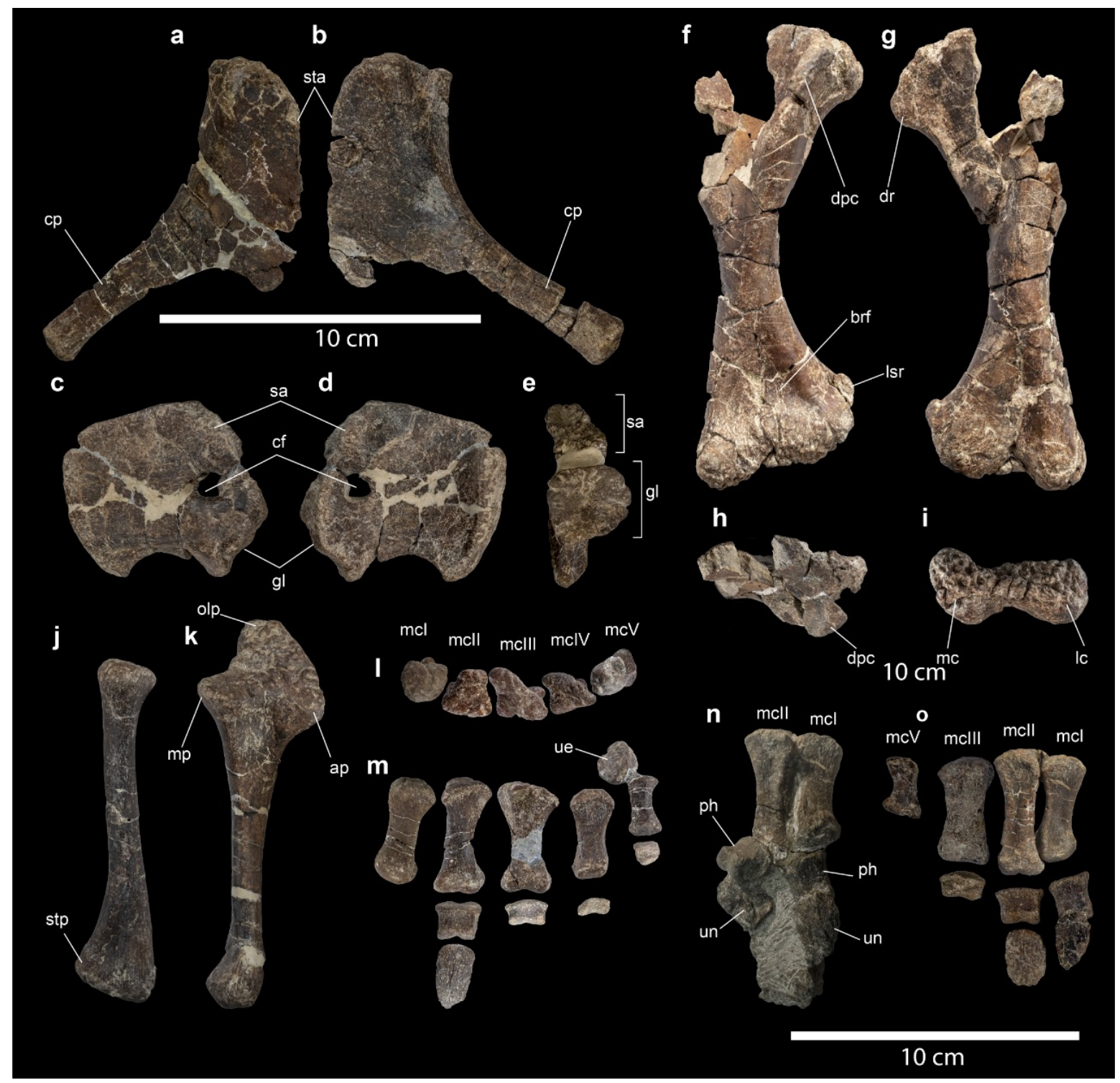

Extended Data Fig. 3 Sternal, pectoral girdle and forelimb bones of Stegouros elengassen gen.

et sp. nov. a, b, sternal plates in ventral view. c-e, right coracoid in lateral, medial and glenoideal views. f-i left humerus in anterior, posterior, proximal and distal views. $\mathbf{j}$, left radius in lateral view. $\mathbf{k}$, left ulna in anterior view. $\mathbf{l}, \mathbf{m}$, left hand in proximal and dorsal views. $\mathbf{n}$, originally semiarticulated right hand in dorsal view. o, fully prepared right hand in dorsal view. Scale bars $=$ $10 \mathrm{~cm}$. ap, anterior process of ulna; brf, brachial fossa; $\mathrm{cf}$, coracoid foramen; $\mathrm{cp}$, caudal process of sternum; dp, dectopectoral crest; dr, descending ridge; gl, glenoid; lc, lateral condyle; lsr, lateral supracondylar ridge; mc, medial condyle; mcI-V, metacarpals I to $\mathrm{V}$; $\mathrm{mp}$, medial process of ulna; olp, olecranon process; ph, non-ungual phalanx; sa, scapula articulation; sta, sternal articulations; ue, ulnare; un, ungual. 


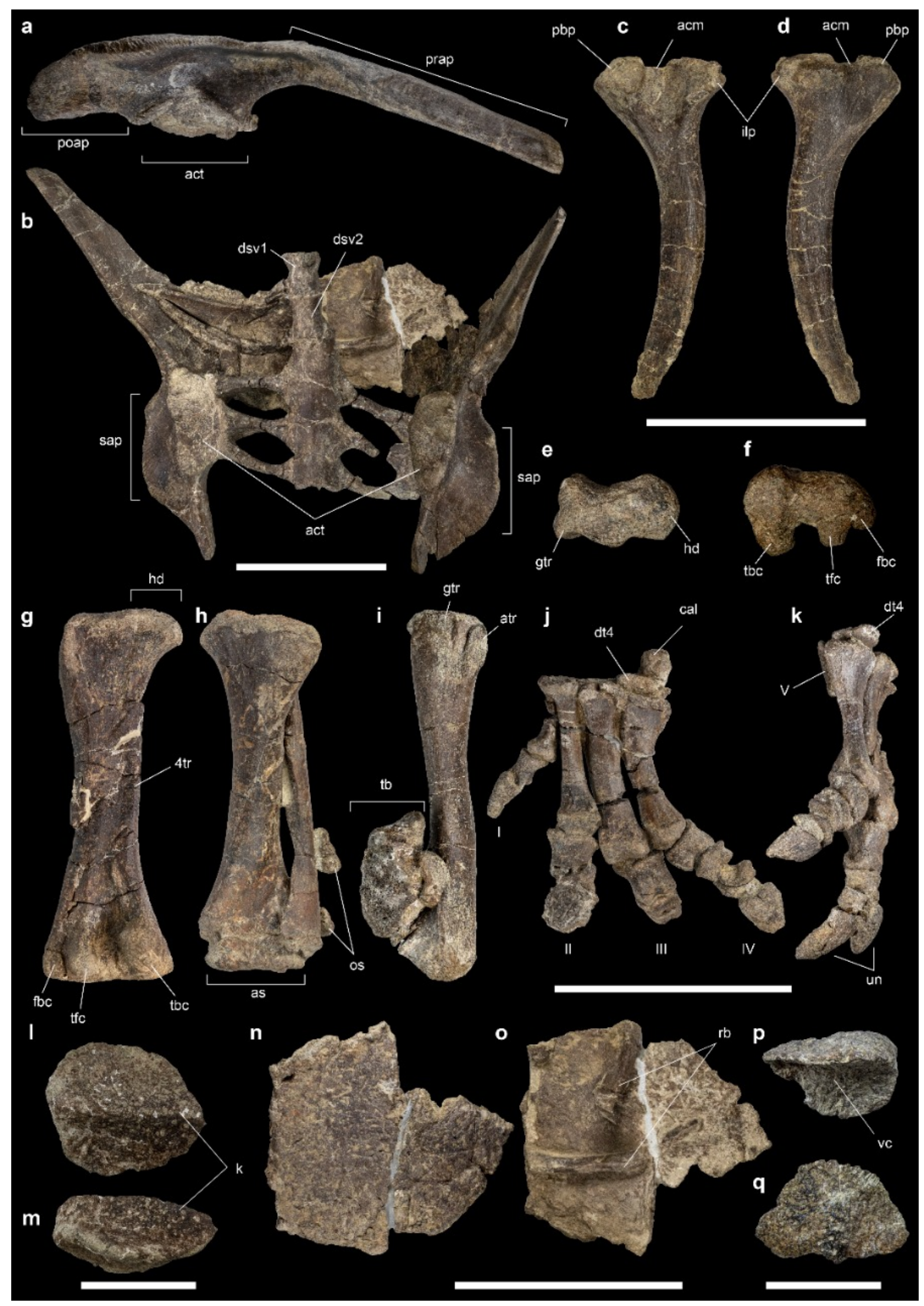


Extended Data Fig. 4 pelvic girdle, hindlimbs and dermal armour of Stegouros elengassen gen.

et sp. nov. a, right ilium in lateral view. b, pelvis in ventral view. c, d, left pubis in lateral and medial views. e-g, left femur in proximal, distal and posterior views. i, right femur in lateral view. $\mathbf{j}$, left foot in dorsal view. $\mathbf{k}$, right foot in lateral view. $\mathbf{l}, \mathbf{m}$, isolated mid-sized ovalate keeled osteoderm in dorsal and lateral views. $\mathbf{n}, \mathbf{o}$, sacral shield in dorsal and ventral views. $\mathbf{p}$, keeled osteoderm with deeply excavated inner surface associated with right ulna in ventrolateral view. q, flat osteoderm associated with right radius in dorsal view. Scale bars for a-k, n, o $=10 \mathrm{~cm}, 1, \mathrm{~m}, \mathrm{p}, \mathrm{q}$ $=2 \mathrm{~cm}$. I-V, digits I to V; 4tr, fourth trochanter; act, acetabulum; as, astragalum; atr, anterior trochanter; cal, calcaneum; dsv, dorsosacral vertebra; dt4, distral tarsal 4; hd, femoral head; fbc, fibular condyle; gtr, greater trochanter; k, keel; poap, postacetabular process; prap, preacetabular process; os, osteoderm; rb, ribs; sap, supracetabular process; tb, tibia; tbc, tibial condyle; tfc, tibiofibular crest; un, ungual; vc, ventral concavity. 


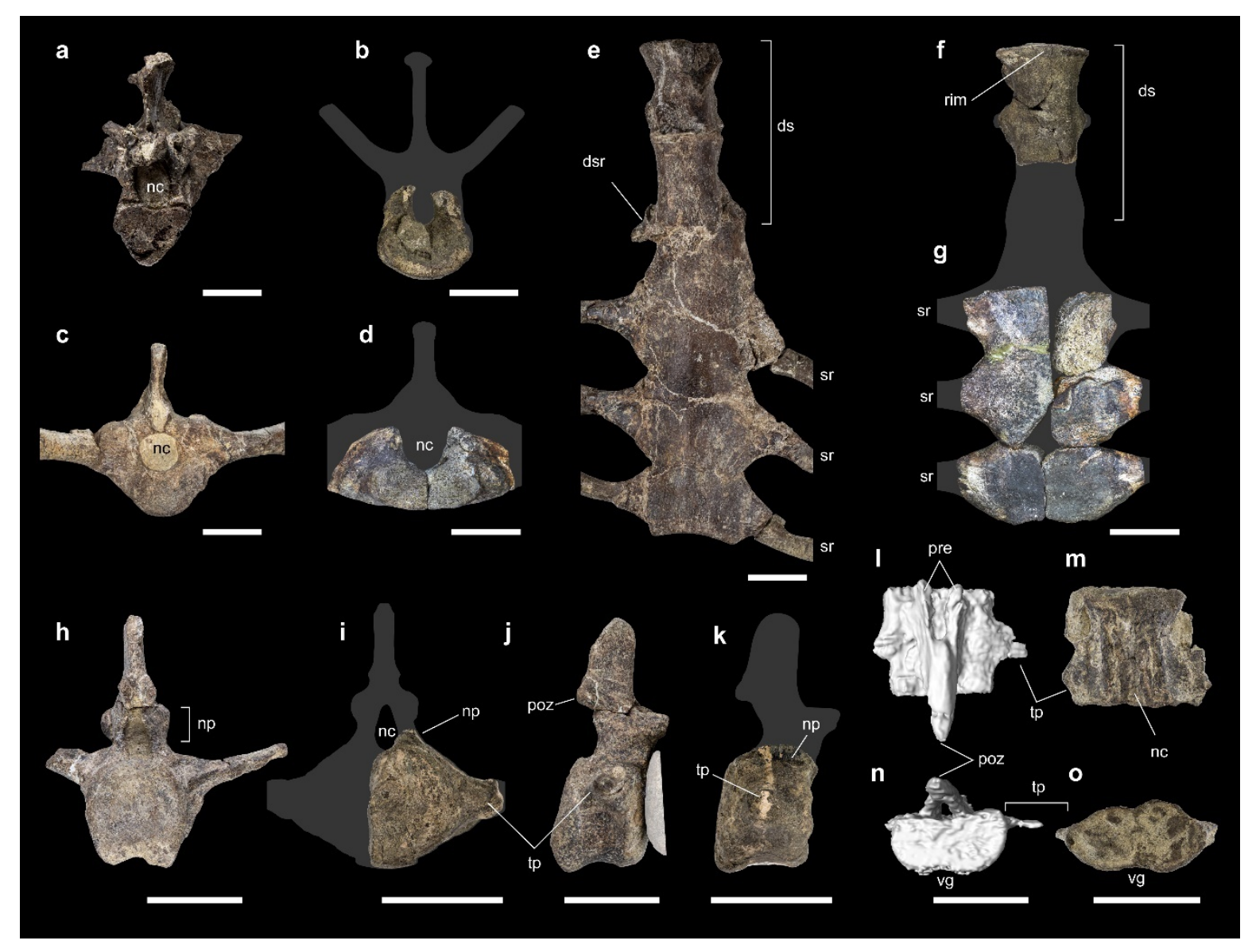

Extended Data Fig. 5 Comparison of axial skeleton between Stegouros elengassen gen. et sp. nov CPAP-3165 and Antarctopelta oliveroi MLP 86-X-28-1. a, c, e, Stegouros elengassen synsacral complex in anterior, posterior and ventral views. b, d, f, g, Antarctopelta oliveroi synsacral elements in anterior, posterior and ventral views. $\mathbf{h}, \mathbf{j}$, Stegouros elengassen 6 th caudal vertebrae in posterior and right lateral views. i, k, Antarctopelta oliveroi anterior caudal vertebrae in posterior and right lateral views. $\mathbf{l}, \mathbf{n}$, Stegouros elengassen 17 th caudal vertebrae in dorsal and posterior views. m, o, Antarctopelta oliveroi posterior caudal vertebrae in dorsal and posterior views. Scale bars a, c, e, h, j, l, n= $2 \mathrm{~cm}, \mathrm{~b}, \mathrm{~d}, \mathrm{f}, \mathrm{g}, \mathrm{i}, \mathrm{k}, \mathrm{m}, \mathrm{o}=5 \mathrm{~cm}$. cv, caudal vertebra; ds, dorsosacral vertebrae; dsr, dorsosacral rib; nc, neural canal; np, neural peduncle; poz, postzigapophysis; pre, prezygapophysis; rim, ventral rim; sr, sacral rib; tp, transverse process; vg, ventral groove. 


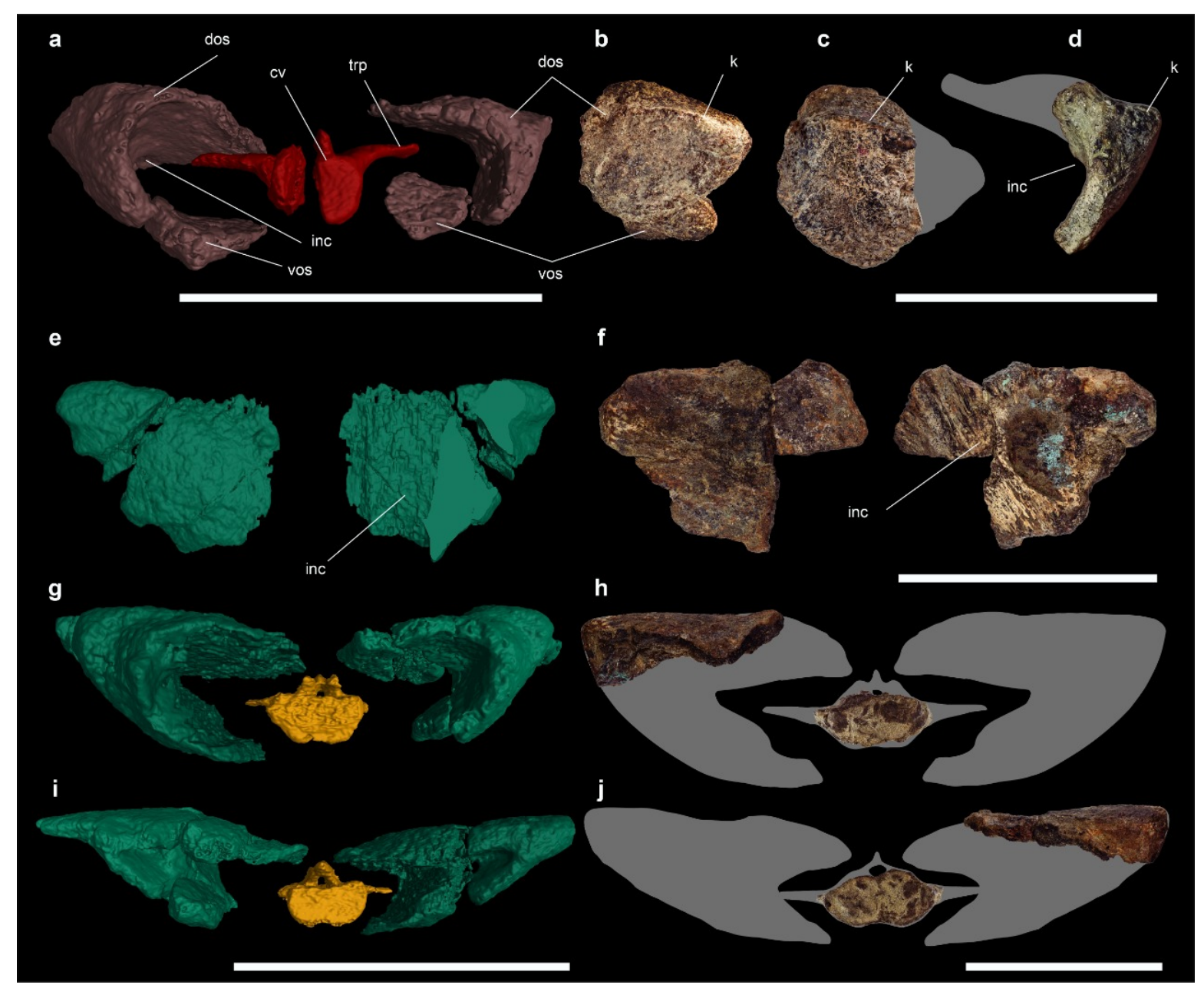

Extended Data Fig. 6 Anatomy of caudal weapon osteoderms in Stegouros elengassen gen. et sp. nov CPAP-3165 and Antarctopelta oliveroi MLP 86-X-28-1. a, b Stegouros elengassen caudal weapon cross section (at level of first osteoderm pair and 14th caudal vertebra) in anterior and left lateral views. c, d, Antarctopelta oliveroi dorsal osteoderm of the first pair in left lateral and anterior views. e, Stegouros elengassen left second osteoderm in dorsal and internal views. f, Antarctopelta oliveroi left second osteoderm fragment in dorsal and internal views. g, i, Stegouros elengassen caudal weapon cross section (at level of second pair and 17th caudal vertebra) in anterior and posterior views. $\mathbf{h}, \mathbf{j}$, proposed configuration of the caudal weapon of Antarctopelta oliveroi in anterior and posterior views. Scale bars $=10 \mathrm{~cm} . \mathrm{cv}$, caudal vertebra; dos, dorsal osteoderm; inc, inner concavity; $\mathrm{k}$, keel; trp, transverse process; vos, ventral osteoderm. 


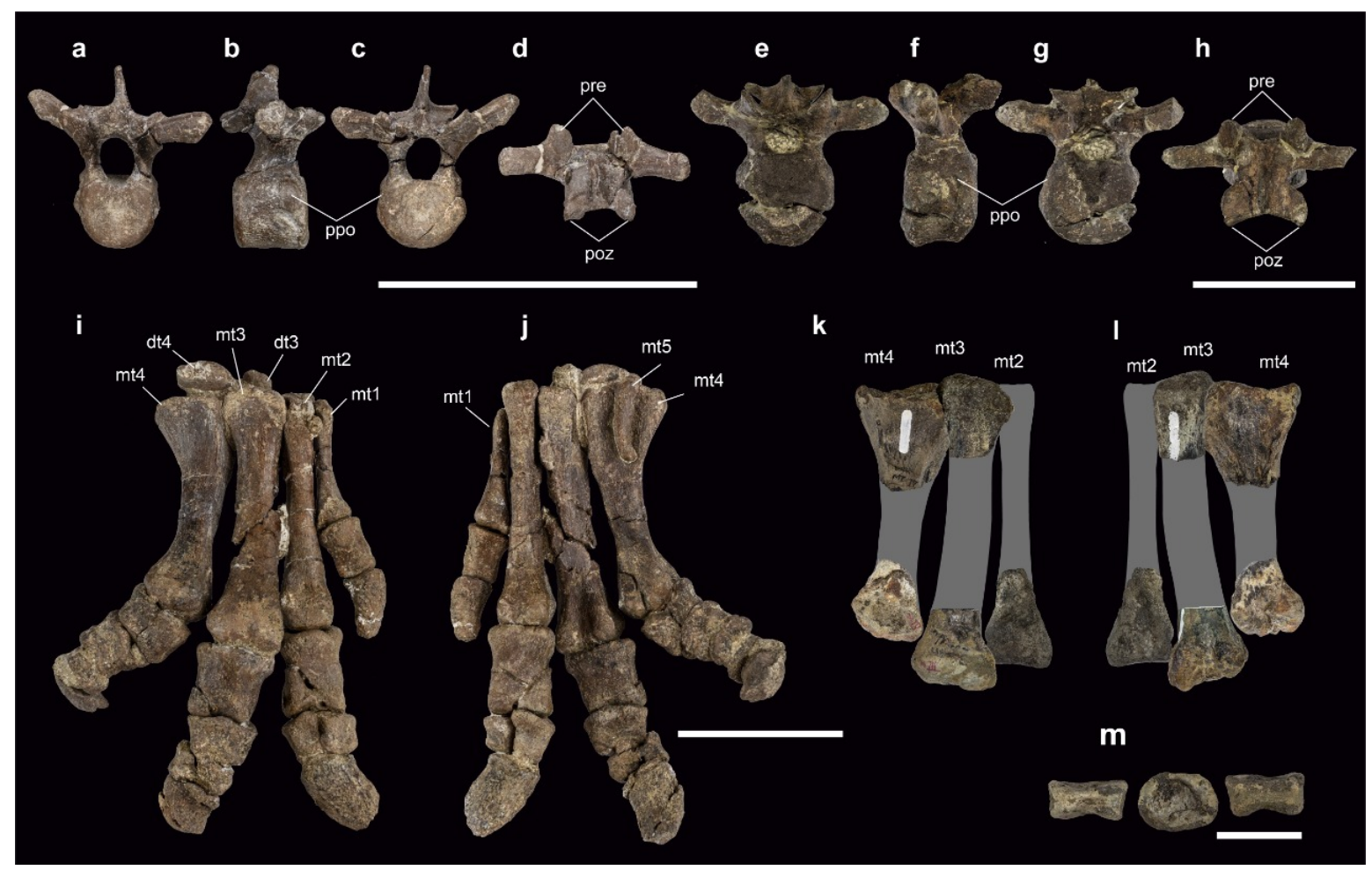

Extended Data Fig. 7 Comparison of cervical and pedal bones between Stegouros elengassen gen. et sp. nov CPAP-3165 and Antarctopelta oliveroi MLP 86-X-28-1. a-d, Stegouros elengassen posterior cervical vertebra in anterior, right lateral, posterior, and dorsal views. e-h. Antarctopelta oliveroi posterior cervical vertebra in anterior, right lateral, posterior, and dorsal views. i, j Stegouros elengassen right foot in dorsal and ventral views. k, l, Antarctopelta oliveroi right metatarsal in dorsal and ventral views. m, Antarctopelta oliveroi isolated pedal phalanx in dorsal, proximal and ventral views. Scale bars $=5 \mathrm{~cm}$. cv, caudal vertebra; ds, dorsosacral vertebrae; dsr, dorsosacral rib; dt4, distal tarsal 4; dos, dorsal osteoderm; inc, internal concavity; $\mathrm{k}$, keel; mt1-5, metatarsals 1 to 5. nc, neural canal; np, neural arch peduncle; pre, prezygapophysis; poz, postzygapophysis; ppo, parapophysis. 


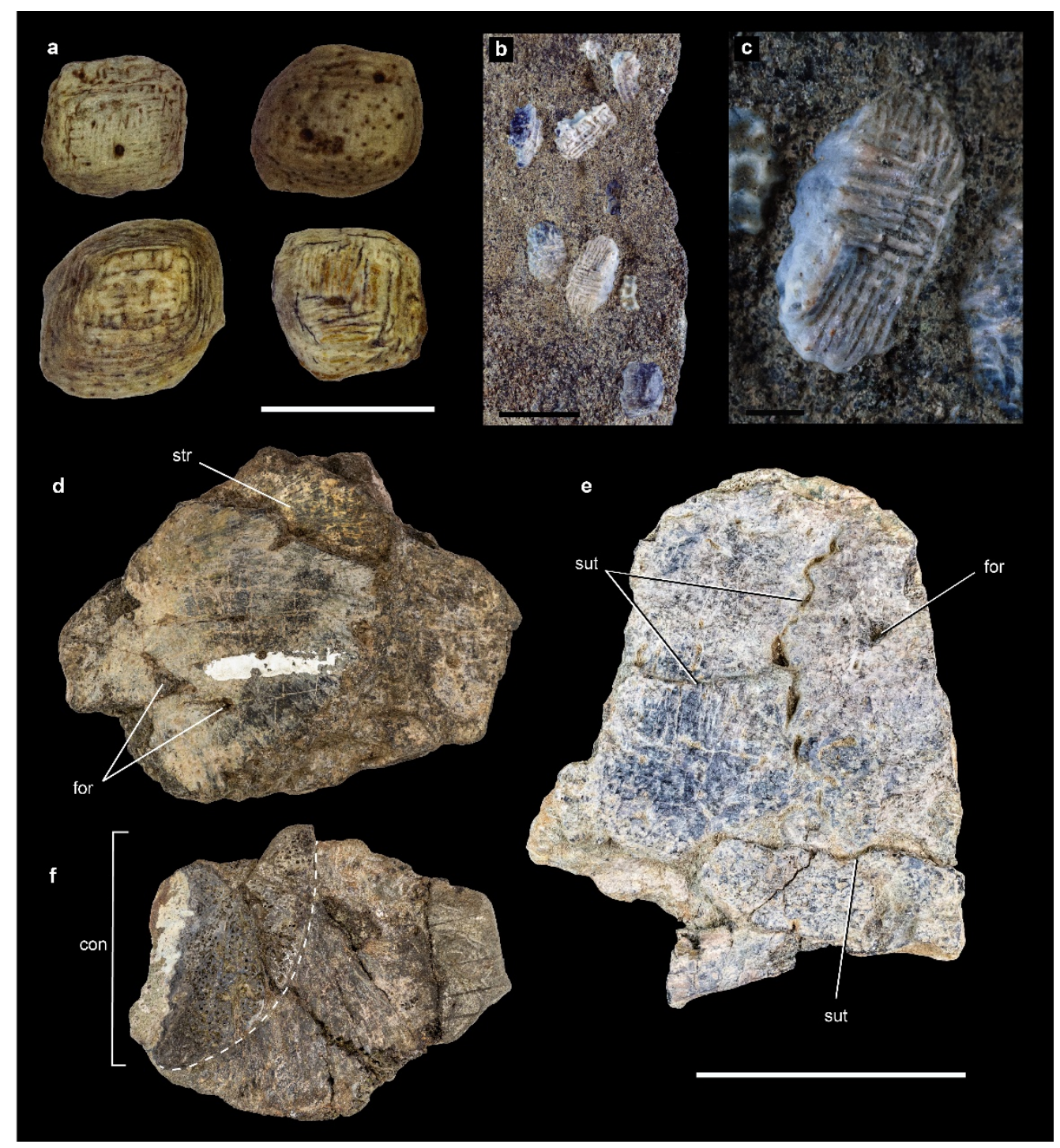

Extended Data Fig. 8 Comparison of dermal skeleton between Stegouros elengassen gen. et sp. nov CPAP-3165 and Antarctopelta oliveroi MLP 86-X-28-1. a, Stegouros elengassen dermal ossicles in internal view. b, Antarctopelta oliveroi disarticulated dermal ossicles. c, Antarctopelta oliveroi dermal ossicle clos-up exposed in internal view. d-f, sacral shield fragments of Antarctopelta oliveroi. Scale bars for a-c $=10 \mathrm{~cm}, \mathrm{~d}, \mathrm{e}=5 \mathrm{~mm} ; \mathrm{f}, 1 \mathrm{~mm}$. con, contact with bone; for, foramina; str, striations; sut, suture line. 


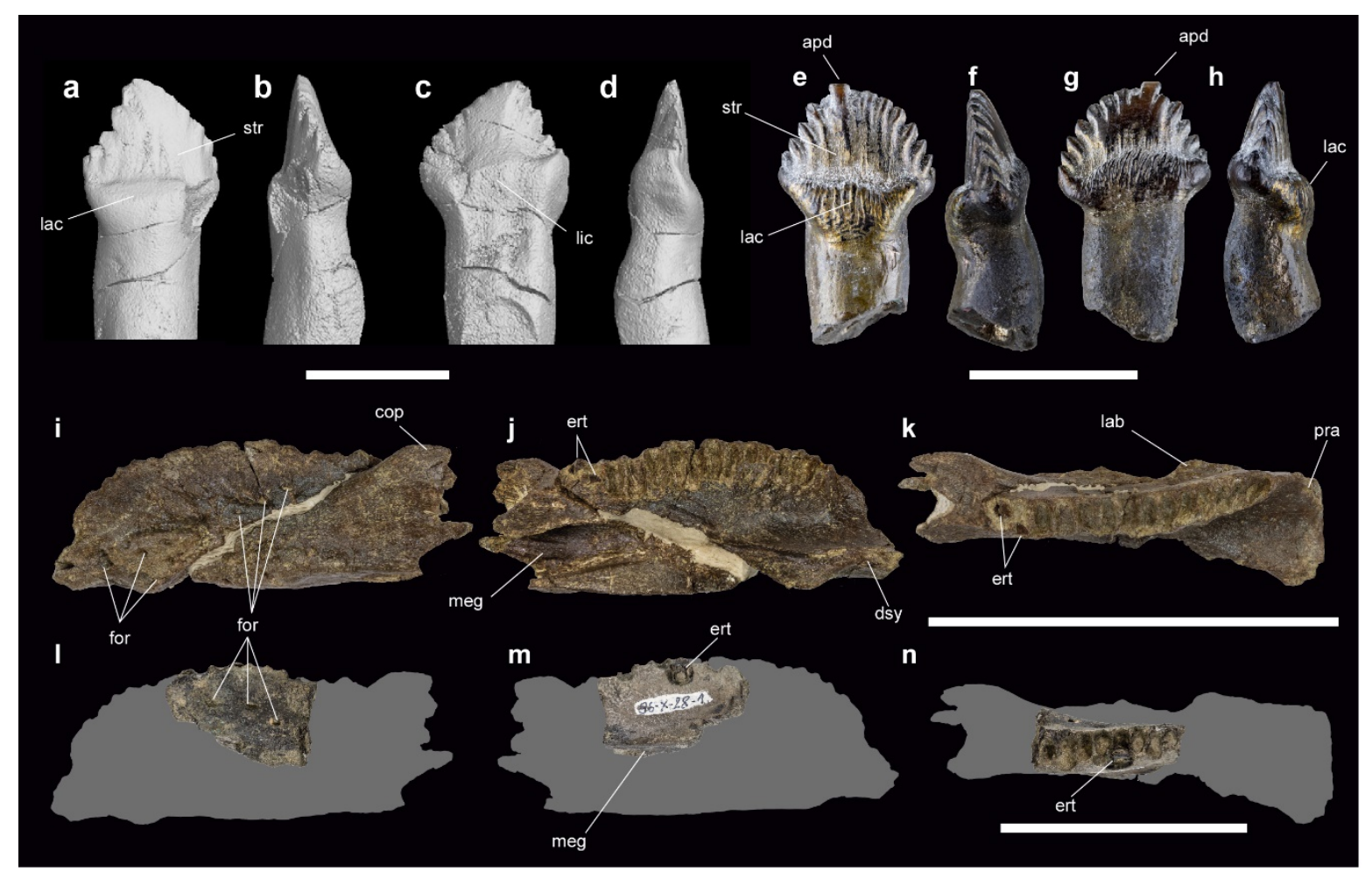

Extended Data Fig. 9. Comparison of teeth and dentary of Stegouros elengassen gen. et sp. nov

CPAP-3165 and Antarctopelta oliveroi MLP 86-X-28-1. a-d, Stegouros elengassen tooth in labial, mesial, lingual, and distal views. e-h, Antarctopelta oliveroi tooth (reversed) in labial, mesial, lingual, and distal views. i-k, Stegouros elengassen right dentary (mirrored for better comparison) in labial, lingual and occlusal views. I-n Antarctopelta oliveroi right dentary fragment in labial, lingual and occlusal views. Scale bars for a-d $=5 \mathrm{~mm}$; $-\mathrm{h}=10 \mathrm{~mm}$; $\mathrm{i}-\mathrm{n}=10 \mathrm{~cm}$. apd, apical denticle; dsy, dentary symphysis; ert, erupted tooth; for, labial foramina; lab, labial boss; lac, labial cingulum; lic, lingual cingulum; meg, meckelian groove; pra, predentary articulation; str, crown striations. 


\begin{tabular}{|c|c|c|c|c|c|c|c|c|c|c|}
\hline Matrix & \multicolumn{2}{|c|}{$\begin{array}{c}\text { Han et al } \\
2018\end{array}$} & \multicolumn{2}{|c|}{$\begin{array}{c}\text { Loewen and } \\
\text { Kirkland } \\
2013\end{array}$} & \multicolumn{2}{|c|}{$\begin{array}{c}\text { Arbour et al. } \\
2016\end{array}$} & \multicolumn{2}{|c|}{$\begin{array}{c}\text { Raven and } \\
\text { Maidment } 2018\end{array}$} & \multicolumn{2}{|c|}{ Norman 2020} \\
\hline Analyisis & A1 & A2 & A1 & A 2 & A1 & $\mathrm{A} 2$ & A1 & $\mathrm{A} 2$ & A1 & $\mathrm{A} 2$ \\
\hline steps & 1255 & 1263 & 689 & 705 & 694 & 702 & 336.370 & 342.260 & 272 & 282 \\
\hline CI & 0.363 & 0.360 & 0.479 & 0.468 & 0.359 & 0.355 & 0.554 & 0.544 & 0.665 & 0.642 \\
\hline RI & 0.711 & 0.708 & 0.745 & 0.733 & 0.651 & 0.645 & 0.647 & 0.633 & 0.830 & 0.812 \\
\hline $\begin{array}{c}\text { Templeton } \\
\text { test }\end{array}$ & not si & nificant & sign & icant & not si & nificant & signi & icant & sigr & ficant \\
\hline $\begin{array}{l}\text { Boostrap } \\
\text { Value }\end{array}$ & 63 & & 87 & & 13 & & 51 & & 46 & \\
\hline $\begin{array}{l}\text { Bremer } \\
\text { Value }\end{array}$ & 2 & & 4 & & 5 & & 0 & & 2 & \\
\hline
\end{tabular}

Extended Data Table 1. Results of Phylogenetic analysis. Summary of phylogenetic analyses for five modified data matrices, indicating number of steps, consistency, retention indexes, and support values for Parankylosauria in the strict consensus of the most-parsimonious trees (A1) and in a forced topology of Stegouros closer to Stegosauria than to Ankylosauria (A2), with Templeton tests to assess its significance. 


\section{Acknowledgements}

This research was funded by ANID (government of Chile) through PIA Anillo grant $\mathrm{N}^{\mathrm{o}}$ ACT172099 and FONDECYT grant $\mathrm{N}^{\circ} 1190891$ to AOV, FONDECYT grant $\mathrm{N}^{\circ}$ 1151389 to MAL, and PhD scholarships for JAM and SSA. We thank Felipe Suazo, Elaine Nuñez, Daniel Bajor, and Juan Pablo Guevara for their help with fieldwork and fossil preparation. We thank Sarah Davis and the Julia Clark team for help in the field. Many thanks to Estancia Cerro Guido for granting access and important logistical support.

\section{Data availability statement}

All data generated or analysed during this study are included in this published article and its supplementary information files. Raw data from CT-Scans is available from the corresponding authors on reasonable request. 


\section{Supplementary Files}

This is a list of supplementary files associated with this preprint. Click to download.

- SotoAcunaetal.SupplementaryInformation17.08.2021.pdf

- SuppMovie3.avi

- SuppMovie1.avi

- SuppMovie2.avi

- flatlists.pdf 